\title{
Ligações perigosas: o diálogo ilusório entre enigma e erotismo na herança midiática das Lettres Portugaises
}

\author{
Ada Cristina Machado Silueira'
}

\begin{abstract}
Resumo: O artigo reflete a partir do caso paradigmático da herança midiática da obra literária Lettres Porthgaises. Estudamos a injunção entre uma obra literária e a cadeia intermidiática que, a partir da primeira, é passivel de notório reconhecimento. Perguntamos qual seria a apropriação da obra literária referida para a cultura midiática contemporànea, especialmente para algumas produçòes cinematográficas originadas da literatura epistolar. Há alyumas respostas que envolvem o trajeto da obra referida como literatura canônica na formaçào escolar e que enoolvem especialmente as relaçòes entre um amor enigmático e o erotismo. As narrativas femininas fazem parte da cultura da midia e a elas se empresta un caráter especial. Reflexo disso é a aparição de Novas cartas portuguesas, três séculos depois c ironicamente causando também um grande impacto. Também referimos à estigmatização das Mariana-Marias e sua condição de anti-sujeito, o ainda presente enigma das identidades de autoria c das personagens e a cultura midiatica em torno ao tema da literatura epistolar e do erotismo.
\end{abstract}

Palavras-chave: literatura epistolar - erotismo - cinema

\begin{abstract}
The article reflect from the paradigmatic case of mediatic heritage of the litcrary work I ettres Portugaises. We study the injunction between a literary work and the intermediatic chain that, from the first, is liable to notorious recognition. We ask what would be the appropriation of said literary work to the contemporary media culture, especially to some cinematographic productions originated from epistolary literature. There are answers that involve the trajectory of said work as canonical literature in school formation and that especially involve relations between an enigmatic lore and eroticism. The feminine narratives are part of media culture and to them a special quality. Reffecting this is the appearance of $N e n$ Porfiguese Lefters, three centuries late and ironically causing a huge impact as well. W/e also refer

1 Jornatista graduada pela Unisinos. Nagister e Doutom em jomalismo pela Unimersiat

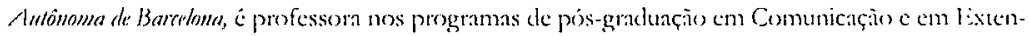
sĩo Rumb da Universidade Federal de Santa Mana. Coorelenadora do N p de Poliefas e estrategitis de Comunicaçio da !ntercom, lider do grupo de pesquisa Comunicaçò, idenudades c frontcitas.
\end{abstract}


to the stigmatizing of Mariana-Marias and its condition of anti-subject, the still present enigma of author and character identities and the media culture around the theme of epistolary literature and eroticism.

Key words: epistolary literature - eroticism - cinema

\section{Introdução}

O artigo reflete a partir do caso paradigmático da herança midiática da obra literária Lettres Portugaises e a injunção determinada entre uma obra literária e a cadeia intermidiática que, a partir da primeira, é passível de notório reconhecimento. Perguntamos qual seria a apropriação da obra literária Lettres Portugaises para a cultura midiática contemporânea. Ou, por outra via, indagamos como o registro literário de um encantamento amoroso redunda em obras realizadas em torno do encantamento midiático.

Entendemos que há algumas respostas que envolvem o trajeto da obra referida como literatura canônica na formação escolar e que envolvem especialmente as relações entre um amor enigmático e o erotismo. Elas passam também pelo entendimento de que as narrativas femininas fazem parte da cultura da mídia e a elas se empresta um caráter especial, cuja prova é a aparição de Novas cartas portuguesas, três séculos depois e ironicamente causando também um grande impacto, a estigmatização das Mariana-Marias e sua condição de anti-sujeito para, por fim, comentar o ainda presente enigma das identidades de autoria e das personagens e a cultura midiática em torno ao tema da literatura epistolar e do erotismo. ${ }^{2}$

\section{As Cartas portuguesas}

Falemos de cartas que ganham vida. Ganham vida pela atualização que simultaneamente se produz entre organismos que se interrelacionam. As cartas adormecem e, de tempos em tempos, a mídia

2 Um conjunto de trabalhos - literários, editoriais, históricos, críticos realizados sobrc a obra em epigrafe é utilizado como condutor de uma perspectiva da cultura gerada pelas mídias e sua ação $\mathrm{em}$ função da obra. Não enfocamos aqui precisamente a questão da construção da narrativa feminina, boom editorial do momento, nem tampouco a representação do gênero feminino na sucessão de iniciativas em torno da obra referida. 
as ressuscita de forma esplendorosa. Um esplendor sempre negado ao afeto que as suscitaram. ${ }^{3}$

Afirmamos inicialmente que, conforme apontou George Batajlle (2000, p. 257), o termo erotismo evoca uma expectativa equivoca, e daí ele vir acompanhado do termo enigma em nosso sub-título. O autor reconhecia na sua conferência de 1955 e que, ainda hoje, pósrevolução sexual, faz-se admissivel, por razões não apenas convencionais, que o erotismo é um tema que se define pelo segredo.

Tomadas como um ícone da paixão sem limites, as lettres de la religiense portmgaise consistem em cinco curtas cartas de amor e desde sua aparição podem ser consideradas um best-seller. Quando o cavaleito amado referido nas Cartas morreu, havia cerca de $50 \mathrm{mil}$ exemplares em circulação. A obra lançou a moda do romance epistolar e enquadra-se no período barroco. Na França, em 1669, apareceram com o título Lettres Portugaises, publicadas pelo Claude Barbin e, a Gabriel-Joseph Guilleragues - Conde de Lavagne, foi atribuída inicialmente sua autoria, uma vez que ele já era conhecido pela autoria de umas cartas denominadas Valentini. Ainda que delas se conheçan muitas traduções, as características da primeira versão permanecem como uma incógnita histórica cujos desdobramentos politicos e sociais atingem a atualidade.

Com o tempo identificaram-se personagens possiveis para o romance e o nome da Soror Mariana Alcoforado imortalizou-se no consenso popular como a autora do "doloroso monumento de pajxão" e o fidalgo francês Noël de Chamilly como seu amado. Tendo personagem como "o conjunto dos atributos que foram predicados ao sujeito no curso de um relato" (cf. DUCROT e TODOROV, 2001, p.210), ao tomar a religiosa de Beja como sua autora e protagonista pôe-se em evidência uma condição de anti-sujeito, cujo mistério acompanha a celebridade da obra e constitui parte de seu exito literárjo. $\Lambda$ questào do sigilo aponta-se assim desde o começo.

"As cartas tomaram Paris de assalto", reitera Myriam Cyr, com uma edição de bolso que falava do amor de uma forma direta, verossimil, surpreendendo e seduzindo as elites cultas. Considera-se que seu sucesso inicial e imorredouro provém de propor ao leitor um pacto narrativo de fácil aceitação, independentemente de ponderar se os fatos ocorreram efetivamente, ou resultaram de pura ficçào.

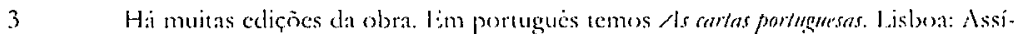
ro \& N.im, 1983. No Brasil, a ediçio mas recente consta do liver de Nyrium Cyr (2007). 
Em Walter Benjamin, "a arte de narrar é a arte de contar experiências" (1994, p. 193). Qual a experiência narrada nas Cartas portuguesas?

A solidão de Mariana, seu sentimento de repressão e sua vontade de reter o amado ao seu lado são constantes. Sua penúria psicológica e queixas amorosas expressas através de atitudes como a traição e os sentimentos eróticos registram o langor da mulher abandonada. $\mathrm{E}$ junto a isto, considera-se que as Cartas são vítimas históricas daqueles que buscam banalizar os processos de sedução por tratarem de um tema proibido tanto quanto de suas transgressões. A expressão da sexualidade pela obra rompeu um padrão e enfrentou a relação de poder entre homens e mulheres ao permitir reconhecer a grave condição daquelas que na época eram assediadas por homens desrespeitosos. $E$ afeta ainda na atualidade aquela tendência que despreza a compreensão de que "El erotismo del hombre difiere de la sexualidad animal precisamente en que moviliza la vida interior. El erotismo es lo que en la consciência del bombre pone em cuestión al ser" (BATAILLE, p.33, grifos do autor). As cartas que muitos atribuem a Mariana Alcoforado e dirigidas ao Conde de Chamilly são exploradas pela mídia por seu apelo e reverência a um amor autêntico e avassalador, contendo tamanha força que, mesmo com os séculos de existência, são consideradas uma referência do amor traído, ainda que esta perspectiva possa instaurar-se num universo obsceno e pleno de referências ligeiras à vida sexual.

As relações estabelecidas em torno à herança midiática redundante do êxito das Cartas implica ativar pensamentos em ação através da conexão entre parecenças e diferenças. Assim, para o caso em análise, o processo de conversão entre uma obra e outra da indústria cultural envolve uma longa cadeia que, inicialmente, permite considerar relações abstratas para as quais há aspectos concretos que podem ser distintivos entre essas obras ou não, e que ainda podem ser obrigatórios ou não-obrigatórios. Antes de propor aspectos de uma possível esquematização, vejamos o caso das Novas cartas portuguesas.

\section{As Novas cartas portuguesas}

As Novas cartas portuguesas foram escritas por Maria Isabel Barreno, Maria Teresa Horta e Maria Velho da Costa. Trata-se de uma obra redigida em conjunto em 1971 e editada no ano seguinte. A obra apresenta-se como uma longa carta inacabada para um destinatário desconhecido, não identificado nem como homem nem como mulher. 
As autoras clamavam num obscuro contexto político que cada un teça sua própria história expressando-se através do experimentalismo lingüístico que viria a renovar a literatura portuguesa nos anos $60 .^{4}$

Ao ter como arquitexto explícito em seu título a consagrada obra do século XVII, a obra desafia mais uma vez as convenções do gênero epistolar, assim como questiona as relaçōes de gênero, e põe num corpo de mulher os grilhões individuais, familiares e sociais contemporàneos.

Maria Isabel Barreno era editora literária de um jornal de Lisboa, enquanto Maria Teresa Horta era psicóloga. Maria Velho da Costa já se havia projetado no cenário literário português em $1969 \mathrm{com}$ a obra Maina Mender. ${ }^{5}$ Elas foram educadas em conceitos burgueses lisboetas, com curso superior, casadas, com um filho varão cada. Encontravam-se duas vezes na semana para trocar e discutir textos. Uma vez na casa de uma delas, outra vez num restaurante público. Presas na primavera de 1972 "por abuso da liberdade de imprensa e ultraje à decência pública", seu julgamento foi adiado várias vezes pelo regime político do salazarismo em decomposiçào. Foram proibidas de ir ao estrangeiro e de ser referidas pela imprensa. Registrou-se a tática de extorsào económica pelas advogadas: "A obra marcou profundamente a sociedade portuguesa da época e custou às respectivas autoras um processo judicial. Elas não viriam a encontrar-se depois deste evento" (cf. Maria João, 1995)."

Houve solidariedade internacional dos grupos feministas, com atuaçào destacada de feministas como Catherine Clément e Monique Wittig, marxistas de base psicanalítica. A última publicou um trabalho sobre o tema em 1973. O julgamento teve data marcada uma derradeira vez e uma semana depois estourou a Revolução dos Cravos ( 25 de abril de 1974). O juiz as mandou para casa, deu ordem de venda do livro e os parabéns às Marias pelas qualidades literárias inigualáveis da obra.

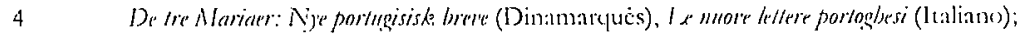

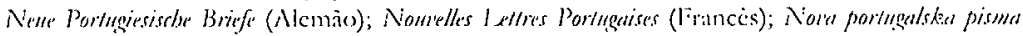

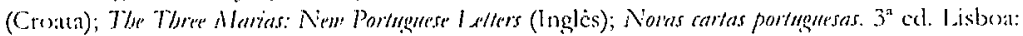

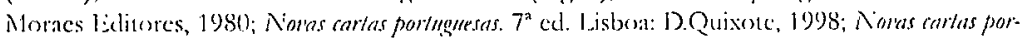

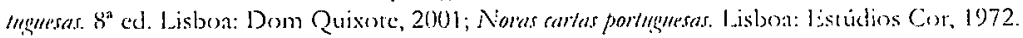
I. a ediçán brasileira Nomas cartas portugneses. Rio de Janciro: Nódica, 1974.

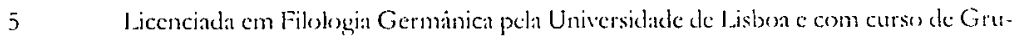
por-Análise da Socicdade Portuguesa de Neurologia e Psiquiauria. Foi leitura do King So College em Londres, presidene da $\lambda$ ssociaçán Portuguesa de liscritotes e adida cultural cm Cabo Verde.

6 Informaçōes proferidas por Naria foào, da Universidade da Califorma, en curso

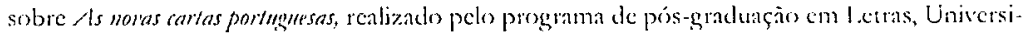
dale Federal de Sinta Maria, em (09.08.1995.
} 


\section{A estigmatização das Mariana-Marias}

A estigmatização de Mariana do Alcoforado, a religiosa apaixonada, e a estigmatização das Marias liberadas, feministas e politizadas supõe a condição de anti-sujeitó que a critica feminista credita à indústria cultural quanto gênero feminino.

Nesta situação de avaliação política, Michel Foucault (1998) pode ser de grande ajuda quando aponta que há uma relação entre processos de assujeitamento ná produção dos discursos. A cultura midiática, pelos elementos históricos que temos no caso das Cartas portuguesas, permite-nos inferir "que as modalidades de poder e os processos de assujeitamento determinados para a constituição de indivíduos ássujeitados que goviernam os discursos referidos seria precisamente o caso da heroína apontada. A ela teria sido estipulada um tipo de normatividade e também uma forma de subjetividade que são, ao mesmo tempo, sua 'desgraça enquanto indivíduo e fonte inesgotável de sua celebridade midiática, tal como Sartre (2002) analisou na tradição de despojamento aplicado a Santa Teresa D'Ávila (contemporânea de Mariana) em seu duplo confronto frente a Deus e frente à Igreja.

A fórmula monofônica, própria da literatura epistolar e característica das Cartas Portuguesas, são um preclaro antecipatório da condião feminina e da expressão dos laços amorosos na Modernidade. A crítica feminista cita o sujeito da Modernidade como nitidamente masculino (HARAWAY, 1991) E este sujeito estaria desempenhado o papel de censor da voz do feminino. No entanto, se a voz feminina se apresenta como um anti-sujeito, vale perguntar qual é o sujeito que opera como motor de movimento da narrativa.

\section{A confusão entre percurso e personagem}

Nesta situação, pode-se pensar que o erotismo se faz sujeito tanto das Cartas portuguesas como de sua herança midiática. Entretanto, o inefável erotismo é contrarjado pela condição discursiva que, ao não lhe conceder a possibilidade de ser segredo, algo que se apresenta impossível para a tarefa das mídias, estabelece um programa narrativo especial capaz de incorporar uma mimesis ativa e recriar narrativamente uma realidade sigilosa e por isto ser reconhecido. 
Paul Ricoeur (1991, p. 173) pondera a partir de Greimas que a correlação entre a intriga de uma ação e a personagem pode chegar a um máximo de radicalidade, a qual se desenvolve "do lado do agente e do lado do percurso narrativo". Do lado do percurso narrativo se destaca a noção de programa narrativo e de "relação polèmica entre dois programas, donde resulta a oposição sujeito e anti-sujeito". Propõe-se a compreensão de que a ação é interação, uma vez que esta traz a "competição entre projetos alternadamente tivais e convergentes". Ricouer destaca neste processo que a semiótica do agente e a semiótica dos percursos percorridos reforçam-se mutuamente ao ponto de confundir-se o percurso com a própria personagem.

E é o que nos vem à mente quando se apresenta o seguinte dilema: "Os estudiosos que tentam descartar a possibilidade do caso entre Chamilly e Mariana sustentam que um homem probo como ele nunca teria ido além das paredes do parlatório" como afirma Myriam Cyr (2007, p. 68). Para além da cultura midiática, ou justificada por sua infuência, há simpósios universitários sobre essa impossibilidade: "Uma pletora de livros e ensaios académicos defende a impossibilidade de uma autoria feminina" (CYR, 2007, p. 16). A fusào entre o percurso percorrido e a própria personagem se estabelece ao ponto da narrativa haver constituído parte do imaginário popular e do universo passional. Ela seria inclusive responsável pela expressão francesa "a la portugaise", utilizada quando se quer expressar naquele idioma uma situação de transbordamento sentimental contido na irracionalidade do discurso e que se tornaria una marca da cultura portuguesa no mundo.

En favor desta fusão, fala o argumento de que também a historiografia trouxe vida a Mariana. Myriam Cyr ficou impressionada com o que chama de "falta de confabilidade dos relatos históricos. A narrativa dos acontecimentos variava grandemente dependendo da fonte" (CYR, 2007, p. 12). E dentre seus detratores, os acadêmicos franceses Jacques Rougeot c Frédéric Deloffre descartaram a possibilidade de que uma mulher pudesse ser autora de una obra de arte grandiosa, tomada como produto de um grande periodo da literatura francesa. Uma religiosa isolada num convento portuguès nào teria capacidade de produzir e compreender um discurso narrativo e ter domínio do código correspondente. Seria de se perguntar sobre suas antecessoras Heloísa, e suas Cartas a Abelardo, além das obras de diferentes religiosas, como por exemplo, Juana Inés de la Cruz (mexicana), a já referida Teresa D'Ávila (espanhola), Hildegarda de Bingen 
(alemã) ou Catarina de Siena (italiana). Estas autoras igualmente há pouco tempo começaram a sair do restrito grupo de eruditos que as conheciam. Embora se deva reconhecer que, dentre elas, nem todas tenham realizado um testamento sentimental passional.

A pesquisadora portuguesa Luisa Alves (2008) registra que a complexidade da obra envolve distintos problemas que remetem à autoria, à língua (português, castelhano,francês). à autenticidade do texto (adaptação ou tradução, amálgama de cartas ou textos integrais), à ordenação das cartas, aos conteúdos ligados à distinção de gênero do autor e,por fim, ao seu possível destinatário.

Não obstante o desconhecimento popular desta produção feminina, o imaginário em favor de Mariana se impôs para dividir águas. E consta que o helenista Boissonade fez o registro definitivo ao encontrar e tornar público em 1810 o registro sobre um manuscrito das cartas no qual se indicava que a autora se chamava "Mariana Alcaforada, religiosa em Beja" [sic].

\section{A identidade de autoria e das personagens}

Um conjunto de trabalhos artísticos (iterários, editoriais, filmográficos, iconográficos) e acadêmicos (históricos, críticos), foram realizados catalisados pela perspectiva da cultura das mídias e sua ação em função da obra assinalada. A controvérsia em torno à identidade de autoria e das personagens da obra é grande.

A existência de Mariana Alcoforado e do Marquês de Chamilly e o fato das cartas serem dirigidas a este último parecem a muitos como indubitáveis. Entretanto, a diferença estrutural entre a história de uma vida e o relato que a conta parece dirimir-se quando um grande debate acadêmico é gerado em torno à problematização da atribuição de autoria dos textos à Sóror Mariana Alcoforado e a sua autenticidade enquanto produção de uma mulher. Voltamos ao que advertem seus críticos quanto ao argumento de que ela não teria competência narrativa para produzir um discurso naqueles padrões.

As dificuldades para com o que pode ser tomado como uma narrativa de ficção e sua verdade poética demonstradas pela critica histórica sugerem algo na esteira daquilo que se pode apontar como um conflito entre projetos. Aponta Hannahn Arend (1991, p. 290) que: 
Sem assumir a priori algum tipo de scqüencia linear de eventos que tenham sido causados necessária e não contingentemente, não scria possivel qualquer explicação que tivesse alguma coerência. O modo óbvio c mesmo o único possivel de preparar c contar uma historia é climinar do que realmente aconteceu os elementos acidentais, cuja enumcração fiel scja ela qual for, é impossível até mesmo para um cérebro computadorizado (grifo da autora).

Um aspecto ainda do que pode ser entendido como projeto rival provém de considerações críticas especializadas. Afrrmaçôes como a que se recupera a seguir são questionadas como impossiveis de ter procedência feminina: "A minha religião e a minha honra, faço-as consistir unicamente em te amar loucamente por toda a minha vida, já que a amar-te comecei!" (Carta IV). Trata-se aqui de uma honra masculina e uma atribuição de papel invertida, pois o a to cortês passa do varão à dama e, desta forma, o jogo de sujeito e anti-sujeito é referendado habilmente e o sentido direciona-se sutilmente em favor da narrativa masculina.

Ruiz-Domenec (1996) reconhece alguns elementos como chaves da narrativa sobre as mulheres e que concedem identidade a sua figura histórica que nos trazem justamente algumas inconvenièncias para a defesa de Mariana. Para o autor, a literatura historiográfica atesta que à mulher estariam reservados atributos vinculados à manutenção da liturgia e à espera, ou o registro da passagem do tempo. Heloísa em sua espera e amor passivo parece dar consistència a ela, mas Mariana não se conforma com este quadro de valores.

A crítica Susan l_ee Carrell (1982) considera que a qualidade lingüistica, sua estrutura aparentemente simples, mas em verdade muito estudada, a forte ilusão de naturalidade fizeram da obra um clássico da literatura francesa, aspectos que Guilleragues - consagrado em sua atribuição de autoria -, dominava com um espírito fino c ainda por sua experiência na corte e no trabalho artístico com Molière. A estrutura da obra, segundo Carrell, se caracteriza ademais da forma epistolar, pelo naturalismo da Modernidade, uma evolução dos sentimentos, uma construção trágica e pessimista do amor e, por fim, 
a construção de uma heroína moderna cuja concepção moral se distancia do cristianismo dominante.

Essa perspectiva estaria atestada por aquilo que Sartre (2002, p. 204) avalia criticamente: "A Santidade cristã é a negação da negação; só recusa, em nós, aquilo só vẹm de nós, isto é, do nosso nada: o erro e as paixões". Precisamente um aspecto ao qual Mariana não se negou. E a prova aparece especialmente quando afirma: "le plaisir de l'amour est d'aimer, et l'on est plus beureux par la passion que l'on a que par celle que l'on donne" (Carta V).

\section{Reconhecimento identitário e cultura da mídia}

Grandes atrizes francesas as interpretaram e nem se produziu a certeza de se foi em português ou se foi em francês que elas foram escritas originariamente. Pintores como "Modigliani, Matisse e Braque tentaram imaginá-la. Rilke e Stendhal (De l'Amour) a homenagearam e sugeriu-se que os Sonetos Portugueses, de Elizabeth Barret Browning, tinham sido profundamente inspirados nas cartas" (CYR, 2007, p. 16).

Choderlos de Laclos produziria no século XVII a obra Les liaisons dangereuses que possui pelos menos duas adaptações para o cinema. Uma, intitulada Valmont, com roteiro de Jean-Claude Carrière para Milós Forman (1989, produção franco-americana) e outra anterior que guardou o título original, com roteiro de Christopher Hampton para direção de Stepehn Frears (1988, produção americano-inglesa), premiada com três Oscars, foi protagonizada por Glenn Close, Michelle Pfeifer e John Malcovich. Estas obras somam-se à herança midiática das Cartas Portuguesas pela via da cultura visual que nos caracteriza neste momento e que Malena Segura Contrera (2007, p.119) observa quando aponta como convocamos a serviço de víncúlos sentimentais toda nossa capacidade de linguagem:

aqui también vemos la búsqueda del control, el intento de, por medio del lenguaje, intervenir en lo real, volverlo a crear de forma a garantizar la participación efectiva del hombre en la creación de ese real. Y esa dinámica que es nuestra gloria puede también ser nuestra mal/dición (porque podemos estar mal/diciendo las cosas). 
E foi dizendo mal de um amor maldito que o conjunto de cartas apontado celebrizaram como realidade e também prova do que o encantamento amoroso pode gerar.

Um feito que a portuguesa Luisa Alves (2008) analisa como "Uma nova abordagem psicológica dos sentimentos individuais, de que será possivel reter para o futuro que o verdadeiro drama está dentro de nós e na forma como vemos o amor."

A fixação de um sentimento trágico para as Cartas e o fantasma identitário engendrado pela obra têm sido objeto de grande correlação e exploração midiática que é passivel de comprovação em muitas produções. $O$ sentido estabelecido primordialmente pelo programa narrativo verificável na herança posta pela cultura midiática aponta para a fórmula esquemática de todo o programa narrativo greimasiano, o qual pode ser enunciado do seguinte modo: un sujeito (S) operante (F) transforma $(=>)$ a situação de disjunção $(V)$ entre um sujeito $(S)$ e um objeto (O) numa relação de conjunção (?). E assim a interação implica a ativação de duas propostas em ação mantendo suas parecenças e diferenças.

Uma hipótese de análise que esta perspectiva aponta envolve considerar a seqüencia dos quatro modos de existencia apresentados por Greimas e Fontanille (1993, p. 132). Da virtualização de um mandante se produziria um sujeito virtualizado que, em sua atualização por um adjutor resultaria um sujeito realizado, passando antes por considerar sua potencialização. Caberiam os exemplos aqui referidos neste esquema? Pensamos que este é um bom ponto de partida para una análise narrativa concreta.

\section{Considerações finais}

As relações abstratas e os aspectos concretos distinguiveis entre as obras referidas e que ainda podem ser obrigatórios ou não-obrigatórios, contam com certas dificuldades para análise. No caso da obra que tomamos por basilar no processo de interação apontado, a adscrição de una açào a um agente, neste caso a questão da autoria e da identidade da protagonista de una grande obra literária, e os debates associados a isso, compõe um largo processo intertextual cujas remissivas acentuam as interações postas pela cultura midiática ocidental.

A muitos, a renúncia a provas de verificação do que está narra- 
do e o reconhecimento do principio de sinceridade de parte de quem os narra se fizeram indeléveis. Como explica Arend (1991, p. 291): "O intelecto, tentando fornecer à vontade uma causa explanatória que lhe abrande a indignação quanto à própria fraqueza, fabricara uma história que faça com que os dados se encaixem. Sem pressupor a necessidade, faltaria à historia toda a coerência.".

Para a existência midiática de Mariana, faz-se imprescindivel que ela tenha tido uma paixão sem limites. Como diz um comentarista português: "um documento pungente do desespero exagerado do amor romântico" (CASTRO, 2007) o que é admissível para a mulher, desde que esse amor seja resignado e de papel, de outra forma, ele se torna duvidoso, enigmático. Pois, conforme observa Malena Contrera:

Por eso el énfasis absoluto que nuestra sociedad da a la comunicación visual, es una de las formas más amplias de incomunicación, ya que - yo creo - la visión no es preferentemente un sentido que se abre a la formación de vínculos comunicativos, pero sí un senido de defensa, utilizado para mantener el control sobre los movimientos de los otros a una distancia segura (CONTRERA, 2007, 118).

E por quê? A autora responde: " $A$ distancia, no bay entrega." (CONTRERA, 2007, 118).

Assim, a interação entre sujeito e anti-sujeito na herança midiática das Lettres Portugaises registra uma intima conexão entre enigma e erotismo que produz o encantamento midiático e faz a fortuna desta última. Nelas se observa uma tentativa de dar à correlação ação-personagem um estatuto de sujeição semiótica que, por sua vez, tem-se mostrado como protagônico na corrente intertextual que apontamos. O projeto a que Propp se dedicou, dentre outros, encontra em nosso exemplo a dificuldade de que, conforme registra Bataille (2000, p. 258) "la experiencia erótica nos obliga al silencio". Por isso, o título tão bem aquinhoado de "ligações perigosas".

A condição equívoca das identidades de autoria e de personagens nas Cartas portuguesas carrega consigo a marca de um diálogo ilusório ou, talvez, mais propriamente, a perseverança do solilóquio em que a condição feminina se vê representada e socialmente reduzida. A incomunicação resultante das relações da herança apontada seria o que propriamente se qualifica como um ponto cego psicológico para o qual atentamos nossos sentidos sem percebê-lo conscientemente. 


\section{Referências}

AREND, Hannah. A vida do espirito. O pensar; o querer; o julgar. Rio de Janeiro: Relume Dumará/UFRJ, 1991.

BARRENO, Maria Isabel; HORTA, Maria Teresa e COSTA, Maria Velho da. Novas cartas portuguesas. Rio de Janeito: Nórdica, 1974.

BARNETT, Richard-l_aurent. Narrative ablation in Guillergagues'Lettres portugaises, The Romanic Reniem, v. 88, 1997.

BATTAILLEE, George. El erohismo. Barcelona: Tusquets, 2000.

BEN]AMIN, Walter. O marnador: consideraçòes sobre a obra de Nikolaj Leskov. Magia e técnica, arte e politica: ensmos sobre literatum e bistória da cultura. São Paulo: Brasiliense, 1994.

CARRELI, Susan Lee. Le solilogue de la passion féminine, on, Ie dialogue illusoire : etude d'une formule monophonique de la tittérature epistolaire. Tübingen: G. Narr; Paris : ].-M. Place, 1982.

CONTRERA, Malena Segura. Amor e incomunicación. In : Dialogos culturales. Inlerdisciplinas para la comminacaion. SARTORI, Rodrigo B., MUÑOZ, Breno O. E., SEPÚlVEDA, Víctor H. V. (Ed.). São Paulo/Valdivia: Annablume/universidad Austral de Chile, 2007. p. $109-120$

CYR, Myriam. A maior paxiono do mundo. A bistórin da freina Mariana do Alcoforado e suas cartas de amor proibido. Rjo de Janeiro: Casa da Palavia, 2007.

DUCROT, Oswald e TODOROV, Tzvetan. Dicionaivo enciclopedico dar ciênciar da linguagem. São Paulo: Perspectiva, 2001.

FOUCAULT, Michel. Microfísica do poder: Rio de Janeiro: Graal, 1998.

GREIMAS, Algirdas \}. e FONTANILLE, Jacques. Semótica das paixòes. São Paulo: Ática, 1993.

HARAWAY, Donna. "A Cyborg Manifesto: Science, Technology, and Socialist-Feminism in the Late Twentieth Century". In: Simians, Cyborgs and Women: The Reimention of Nature. New York: Routedge, 1991. p.149-181

RICOEUR, Paul. O simesmo como mm ontro. Campinas: Papirus, 1991.

RUIZ-DOMÉNEC, José Enrique. El despertar de las mujeren. Barcelona: Peninsula, 1996.

SARTRE, Jean-Paul. Saint Gent. Ator e mâtir. Petrópolis: Vozes, 2002. 


\section{Referências eletrônicas}

ALVES, Luisa. Mariana Alcoforado e o 'Amor Português'. na Ficção Actual em Língua Inglesa. http://www.fcsh.unl.pt/congressoceap/Mariana_luisaalves.doc. Acesso em 23.04.2008.

CASTRO, Alex. http://www.sobresites.com/alexcastro/artigos/cartasport.htm. Acesso em 16.11.2007.

Lettres de la religieuse: portugaise. http://abu.cnam.fr/cgibin/go?lettresreli2,21,40. Acessò em 25.12.2007. 